\title{
Construyendo la paz a través de técnicas creativas, artísticas y vivenciales: aproximaciones al caso Colombiano
}

\section{Building peace through creative, artistic and experiential techniques: approaches to the Colombian case}

Laura Soriano Ruiz

Universitat Jaume I, España

Samuel Silveira Martins

Universidad Internacional del Ecuador, Ecuador

Autor para correspondencia: Laurasorianoruiz@ hotmail.com, Sasilveirama@ uide.edu.ec.

Fecha de recepción: 23 de julio de 2018 - Fecha de aceptación: 20 septiembre de 2018

Resumen: Las iniciativas civiles focalizadas en el uso de técnicas artísticas y vivenciales orientadas a la construcción de paz y el empoderamiento de la sociedad civil han logrado resultados positivos en la población afectada por la violencia de los actores armados en el escenario del proceso de paz en Colombia. En este contexto, esta investigación tiene como objetivo analizar iniciativas de promoción de la paz, mapeando y categorizando las intervenciones que utilizan la arte como principal instrumento de reparación simbólica y que tiene como horizonte la construcción de la paz transformadora e inclusiva, la reconciliación y la construcción de memoria histórica de las víctimas del conflicto armado, además de la transformación los liderazgos a través de procesos participativos y vivenciales. Utilizando metodologías cualitativas basada en la comunicación crítica y análisis del discurso, se ha reconocido, sistematizado y descrito procesos territoriales de construcción de paz y el empoderamiento y que dialogan en el marco teórico y práctico de los estudios de paz, señalando que las técnicas creativas y artísticas pueden ser herramientas eficaces para la construcción de memoria histórica, el empoderamiento, la transformación social y la visibilización de las violaciones de Derechos Humanos en Colombia.

Palabras clave: arte; creatividad; estudios de paz; empoderamiento; Colombia

Abstract: The civil initiatives focused on the use of artistic and experiential techniques, aimed at building peace and the empowerment of civil society have achieved positive results in the population affected by the violence of armed actors on the stage of the peace process in Colombia. In this context, the research aims to analyze initiatives that promote peace, mapping and categorizing those that use art as the main instrument of symbolic reparation and has at the skyline the transformative and inclusive peace building, reconciliation and construction of collective memory of the victims of the armed conflict, in addition to the transformation of leadership through participatory and experiential processes. Through qualitative methodologies based on critical communication and discourse analysis, we have recognized, systematized and described territorial processes of peace building and empowerment that dialogue with the theoretical and practical framework of peace studies, pointing out that creative and artistic methodologies and techniques can be effective tools for the construction of collective memory, empowerment, social transformation and the visibility of Human Rights violations in Colombia.

Key Words: art; creativity; peace studies; empowerment; Colombia 


\section{Introducción}

El papel que tiene la sociedad civil en Colombia como gestor y promotor de la paz es crucial y uno de los sectores sociales de gran relevancia en la apuesta por la paz son las mujeres, jugando un papel importante en las movilizaciones sociales de carácter nacional, así como en iniciativas en contextos locales.

En este contexto hay numerosas y heterogéneas iniciativas de base social que trabajan por la paz utilizando metodologías alternativas como expresiones artísticas y culturales para la promoción de la paz y el empoderamiento de la sociedad civil, donde muchas mujeres y jóvenes en el proceso de construcción de la paz han apostado por la filosofía de la no violencia como elementos esenciales para hacerle frente al conflicto armado colombiano y para la reconstrucción social a través de procesos de reeducación, dinamización de valores morales y símbolos de paz, además del rechazo a la violencia.

Considerando estas premisas, el presente artículo analiza como las prácticas estéticoartísticas y vivenciales (PEAV), como el teatro del oprimido, el teatro de lo afectivo, las artes plásticas, grafitis, música, terapias corporales, entre otras, han demostrado reforzar el tejido social, sanar a través del arte y memorializar a las víctimas del conflicto armado colombiano, basándome en que el arte, así como las técnicas creativas y vivenciales son instrumentos y herramientas para la incidencia política, la transformación de liderazgos, el empoderamiento y visibilización de las violaciones de derechos humanos (Kabeer, 2000; Ocampo, 2010, Silva, 2012; Muñoz, 2013; Meneses, 2014): En definitiva, cómo el arte aporta para la transformación social, desde lo vivencial, como un espacio simbólico de lucha y resistencia.

Siendo esta una investigación exploratoria, intentamos responder a la problemática de cómo el arte y las PEAV aportan al proceso de empoderamiento de las personas y en concreto de las mujeres, analizando iniciativas implementadas en diferentes territorios del país, corroborando que estas técnicas, independiente del contexto específico de cada localidad y sus beneficiarios, pueden contribuir al empoderamiento por ser un vehículo donde las personas pueden manifestarse a sí mismos/as, a partir de experiencias que superan lo meramente discursivo; experiencias que son interiorizadas, y durante las cuales el sujeto aprende a través de la emoción provocando que las personas expresen su propia realidad, hablando desde el yo.

Asimismo, las PEAV también sirven a las víctimas para visibilizar y denunciar su situación y condición tanto subjetiva como objetiva, posibilitando un proceso de transición a partir del empoderamiento de las personas, de la condición de víctimas a la de constructores de paz, demostrando que las técnicas creativas y artísticas al trabajar las subjetividades a partir de lo simbólico y desde una estrategia que busca la transformación y resignificación del dolor y del sufrimiento en el proceso del duelo, convirtiendo la expresión artística en una forma de comunicación que permite la construcción de memoria histórica a través de los sentimientos, emociones, vivencias, miedos, alegrías del sujeto victimizado/victimario.

Como resultado describimos 10 iniciativas de construcción de paz y las técnicas creativas, artísticas y vivenciales empleadas por estas, a la luz de la construcción de paz transformadora e inclusiva a través de procesos participativos y vivenciales en el contexto 
concreto colombiano. Se pretende demostrar como el arte, las técnicas creativas y vivenciales son instrumentos y herramientas comúnmente usadas para la incidencia política ante violaciones de derechos humanos y de la violencia de género en el marco específico del conflicto armado.

\section{Consideraciones Metodológicas}

Dado que es una investigación exploratoria y eminentemente cualitativa, utilizamos la triangulación de datos como praxis metodológica, considerando el control cruzado de datos de distintas fuentes comparando y contrastando respuestas (Ruiz, 1999), lo que ha contribuido para la objetividad en la análisis de los datos obtenidos a través de entrevistas semiestructuradas (Bryman, 2005) realizas a cuatro lideresas beneficiarias, representantes de movimientos feministas, representantes de organizaciones sociales que trabajan en el área de empoderamiento, género y construcción de paz, y académicas que investigan el área de construcción de paz en Colombia y la participación de la sociedad civil en la misma.

A través de las entrevistas recogemos datos cualitativos que nos posibilitaron conocer las diferentes matices sobre en el impacto del uso de técnicas creativas y artísticas para la transformación de liderazgos y resolución pacífica de conflictos, memorialización y visibilización de violaciones de derechos humanos.

Los dados fueron analizados a la luz de la teoría comunicativa crítica (Gómez, 2009) y el análisis del discurso y poder (Foucault, 1979; 2006), donde, según Foucault, hay una necesidad de entender cómo ciertas formas de conocimiento invocan para sí mismos la promoción de la verdad y la legitimidad del conocimiento, ya que estas formulaciones y usos de los saberes ya están dotados de poder, y el poder es un elemento clave del discurso: "La verdad no existe fuera del poder o sin poder". (Foucault, 1979, p. 12).

Sumado a estas técnicas, hicimos la recuperación de fuentes bibliográficas, que "consiste en detectar, obtener y consultar la bibliografía y otros materiales escritos útiles para los propósitos del estudio, de donde se debe extraer y recopilar la información relevante y necesaria que atañe al problema de investigación" (Sampieri, 2003, p. 14).

Esta investigación ha posibilitado mapear 10 experiencias de iniciativas civiles de construcción de paz y empoderamiento a partir PEAV en diferentes regiones del país, como es el Pacífico, Caribe, región Andina y la Amazonía, además de dos iniciativas de ámbito nacional, analizando a su vez las experiencias de acción colectiva de la sociedad civil en favor de la construcción de paz desde los territorios y con el objetivo de visibilizar, reconocer y sistematizar los procesos territoriales de construcción de paz y empoderamiento a través de estas metodologías, destacando los liderados por mujeres.

\section{Instrumentos Del Arte Y Técnicas Creativas Para La Construcción De Paz Y La Memoria Histórica En Colombia}

La sociedad civil colombiana ha sido en las últimas décadas y es actualmente un actor clave de los procesos de construcción de paz, debido principalmente a que la población ha sufrido numerosas y diversas violaciones de derechos humanos y por ello, muchas organizaciones de la sociedad civil persigue un objetivo común que es la construcción de paz a nivel local y nacional (Ruano, 2015). 
En el contexto nacional se destaca la incidencia de importantes redes de mujeres como son las siguientes; La Ruta Pacífica de las Mujeres por la paz (desde 1996), la iniciativa de Mujeres Colombianas por la Paz (desde 2002), Red Nacional de Mujeres (desde 1991), Mujeres de Negro (desde 1995), Mesa Nacional de Concertación de Mujeres (desde 2000), siendo estos solo algunos ejemplos de la capacidad organizativa de las mujeres en el país.

En los territorios, es destacado el papel de las mujeres como gestoras de paz, como es el caso de la Asociación de Mujeres Organizadas en el Oriente de Antioquia - AMOR (1997) y las Madres de la Candelaria (1999), una organización de carácter regional cuyo centro de trabajo ha sido la organización de las víctimas del conflicto y la lucha constante por exigir verdad, justicia y reparación.

Transversalmente, la etnicidad y las luchas identitárias han sido elementos aglutinadores de la colectividad, destacando la participación de poblaciones afrodescendientes e indígenas tanto en el Departamento del Cauca, Chocó y Nariño, en territorios donde las comunidades buscan reconstruir las fuerzas colectivas y los derechos colectivos a partir de su propia cosmovisión. Martha Giraldo, coordinadora de la Ruta Pacífica de Mujeres, considera que para la labor de su organización:

"el trabajo simbólico que hemos logrado realizar a través del arte, reconocimiento de las identidades históricas, de los indígenas, mujeres negras y campesinas nos ha permitido ir recogiendo un material y unas formas de lenguaje que van en lo simbólico, lo político, que van en poder ayudar a bajar temas de violencia, poder ayudar a tender fuentes. Para nosotras el arte es una de las herramientas más importantes porque genera un gran distanciamiento del problema mismo que se vive pero un distanciamiento que invita a una reflexión profunda." (Martha Giraldo, Entrevista Personal, 2015).

Es desde esta diversidad cultural que la arte es accionada como constructora de simbologías que son capaces de promover la paz, tanto subjetivamente como objetivamente, en las realidades concretas de los individuos y sus comunidades. Así nos preguntamos: ¿Cómo definir qué aporta el arte y las prácticas estético-artísticas y vivenciales al proceso de empoderamiento de las personas y en concreto de las mujeres, utilizando ejemplos del contexto colombiano?

Para responder esta preguntar es necesario hacer una bricolaje conceptual, pasando por Alejandra Toro (2015) que define como el arte tiene una gran capacidad de conmover, de provocar, de generar sensaciones, así como también de ser un vehículo de transmisión de amor, fragilidad y ternura, además una herramienta para el empoderamiento pacifista (Toro, 2015, p. 17). Más allá, Muñoz (2013), comentando a respecto a las víctimas del conflicto armado colombiano, considera que la "expresión artística se convierte en una forma de comunicación de sus propias vivencias, conflictos, desventuras, miedos o alegrías donde las prácticas estéticoartísticas también sirven a las víctimas para visibilizar y denunciar su situación "y condición a raíz del conflicto armado colombiano (Muñoz, 2013, p. 6). Alba Ruano, reconocida investigadora de la Universidad del Externado en Colombia, va más allá y consideran que: 
“lo simbólico, lo cultural y lo artístico ayuda mucho a la reivindicación que va más allá de lo estructural, físico y de hecho considero que debería el Estado haber empezado por ahí; por trabajar en términos de subjetividades y afectaciones interiores de los seres humanos como víctimas y ese atender, esa subjetivación o esa parte interna o interior del ser humano se puede hacer a través del arte, de lo simbólico, de la cultura; me parece que esa sería una estrategia efectiva y de hecho lo ha sido." (Alba Ruano, Entrevista Personal, 2015).

Partimos del principio que el arte es una herramienta de comunicación y de transmisión de sentimientos y emociones, y también una "herramienta para generar espacios y alternativas de lucha y resistencia formales e informales“" (Mejía, 2015, p. 7). Asimismo Vanessa Mejía expone que "existe una relación con el arte en escenarios sociales, en los cuales se pone en conexión lo comunitario y lo simbólico, dando poder al papel de la creatividad en busca de alternativas de empoderamiento popular" (Mejía, 2015, p. 2).

¿Sería la arte entonces un instrumento eficaz para la paz y la memoria histórica? Considerando esta indagación, Ana María Costa, investigadora del Agencia Nacional para la Superación de la Pobreza Extrema de Colombia, nos asegura que:

“cuando empezó el tema de la memoria acá en Colombia muchas organizaciones empezaron a trabajar una memoria a partir de eso, del arte, la creatividad, de expresar esas cosas que lamentablemente la violencia había callado en las personas. Entonces era sacarlo de manera totalmente diferente a través de la música, danza, pintura, tejidos. Y yo creo que eso fue lo que permitió que muchas de las víctimas empezaran a hablar y además a conocerse interiormente poder compartir colectivamente sus errores y decir bueno acá necesitamos realmente empezar a hacer algo. Entonces sí creo que es fundamental la creatividad y otras formas además porque más allá de empoderar te resignifica como sujeto de derecho, como sujeto que puede aportar a un cambio a estas cosas." (Ana María Costa, Entrevista Personal, 2015).

Colombia es un país culturalmente diverso o multicultural y muchas de las plurales iniciativas civiles de paz están enfocadas hacia la educación, la resistencia, la protesta y la movilización. Estos procesos afincados en el territorio nacional han sido invisibilidades como obyecto de estudios académicos, pero son fundamentales para la construcción de paz y al mismo tiempo también contribuyen al empoderamiento de la sociedad civil.

Uno de los ejemplos de la diversidad y de la abundancia de espacios artísticos en Colombia fue la celebración de la cumbre mundial del arte y la cultura para la paz en el mes de Abril de 2015, apoyado por el Instituto Nacional de Artes de Colombia, en la cual artistas de diferentes gamas reivindicaron que el arte tiene un rol muy importante como constructor de paz en Colombia. La cumbre permitió dar expresión a los hombres y mujeres, vinculados a procesos de construcción de la paz a través del arte en diferentes esferas como la justicia social, los procesos de reparación y la creación de condiciones de no repetición, así como también permitió la visibilización de artistas que fueron silenciadas por las condiciones del conflicto armado colombiano. 
La investigadora, Esperanza Hernández (1988) ha recogido diversas experiencias de la resistencia civil para la paz en Colombia, afirmando que existen "múltiples escenarios, procesos e iniciativas, y múltiples actores que dan cuenta de un importante poder pacifista y transformador" (Hernández, 1988, p. 2-9). La autora destaca iniciativas civiles de paz de base social y las resistencias para la paz:

Los pueblos, las comunidades, las mujeres, los jóvenes, las víctimas, han padecido en mayor medida las violencias y son los actores relevantes para la construcción de la paz. Entre ellos, es importante destacar a las comunidades campesinas, a la población afrodescendiente y a la indígena, las cuales han sufrido enormemente el contexto del conflicto armado y que a su vez han generado propuestas de construcción de paz (Hernández, 1988, p. 29).

Un ejemplo de estas iniciativas civiles de poblaciones afrodescendientes e indígenas, es la Asociación de Desplazados del 2 de Mayo, en la cual reúne más de 800 personas, en su mayoría mujeres en Bojayá, en el departamento de Chocó. Esta iniciativa realizó diversos ejercicios de memoria histórica y actos simbólicos de reparación, así como también han promovido la recuperación de las tradiciones culturales propias de las poblaciones afrodescendientes (Meneses, 2014, p. 86).

A partir del estudio de Angelika Rettberg (2006) sobre experiencias de construcción de paz desde la sociedad civil en Colombia y su inventario de iniciativas de paz, así como también del Centro de Memoria Histórica de Colombia, y de la sistematización de las iniciativas locales de construcción de paz desde la perspectiva de las mujeres, denominado "Gestando la Paz, haciendo memoria”, promovido por ONU Mujeres Colombia” (Meneses, 2014) , y a través del levantamiento bibliográfico y entrevistas realizadas en esta investigación, expondremos un mapa de experiencias nacionales de iniciativas civiles que utilizan propuestas estético-artísticas y creativas para abordar elementos de cultura de paz (memoria, denuncia, organización social, sanación, incidencia, tejido social, autoestima, etc.) siendo todas ellas aportaciones del arte para la construcción de paz. Organizaremos estas iniciativas según las regiones de Colombia, así como también detallaremos aquellas que son iniciativas de mujeres.

En primer lugar, cabe citar que tras la realización de las entrevistas, observamos que la zona geográfica del Pacífico colombiano se destaca como un espacio donde hay un gran número de técnicas creativas, artísticas y vivenciales siendo utilizadas como vía de sanación del estrés postraumáticos, sobretodo porque según Esperanza Hernández, las poblaciones afrocolombianas mantienen "prácticas comunitarias de solidaridad, resistencia cultural y ancestral" (Hernández, 1988, p. 11). En esta región se destacan las siguientes iniciativas civiles de construcción de paz y empoderamiento:

\section{El Caso Trujillo, Departamento del Valle del Cauca.}

En Trujillo se han producido reparaciones simbólicas importantes a partir del arte en esta localidad, y ha habido manifestaciones teatrales y expresiones artísticas con el objetivo de la memoria y la dignificación de las víctimas (González, 2008). Por ejemplo en 1997, Carlos Ulloa y Stela Guerra, artistas que realizaron memoria de las víctimas junto a la comunidad a través del teatro y la pintura (González, 2008). 
En los años 2001, la escultora Adriana Lalinde, realizó altorrelieves en colaboración con las familias para representar las vidas de las víctimas (González, 2008). En el 2002, otra artista Maritxe Trigos realizó talleres comunitarios, en los cuales cada familia reconstruía su verdad y la vida de su familiar muerto (González, 2008) a través del dibujo y la escritura de textos personales, demostrando una insubordinación frente al silencio que les habían impuesto y reclamando verdad, justicia y reparación.

Igualmente, Magdalenas por el Cauca ha realizado expresiones artísticas acerca de la Masacre de Trujillo. El 17 de abril de 2010 se celebró la décima peregrinación Nacional e Internacional de AFAVIT (Asociación de familiares de víctimas de Trujillo) en homenaje a las víctimas de la masacre de Trujillo. Dicha peregrinación termina en el río Cauca con la exposición artística de Magdalenas por el Cauca en representación de los cuerpos que bajan por el río y las mujeres que buscan los cuerpos de sus familiares en dicho río. Se trata de un proceso de recuperación de memoria.

Por último, Rodrigo Grajales, fotógrafo que ha plasmado en fotografías un homenaje a las víctimas de la masacre de Trujillo ocurrida el 17 de Abril de 1990. El objetivo del artista fue hacer reflexionar sobre los 20 años de la masacre de Trujillo, que dejó 342 víctimas por desaparición y asesinato. En la serie de fotografías se muestran niños que cubren su rostro y sus ojos ante la vulneración, transgresión y violencia vivida. La exposición se focaliza en la memorialización de las víctimas y como forma de liberar el dolor por parte de la población de Trujillo.

\section{El Teatro por la Paz de Tumaco, Departamento de Nariño.}

Se trata de una iniciativa de memoria que trabaja el teatro como herramienta artística para la sensibilización, la denuncia y para la construcción y recuperación de la memoria histórica. Este grupo teatral reconstruye los hechos violentos ocurridos en Tumaco. En el trabajo teatral se presentan las raíces y la historia, así como también los anhelos de paz con dignidad, verdad y justicia. El grupo se compone por mujeres, mayores y jóvenes y las obras tienen una duración entre 35 y 40 minutos.

Entre las obras realizadas se encuentran: "Mi otro yo" (2011), un homenaje a la hermana Cerón y a las víctimas de la violencia y a sus familias. Otro de los ejemplos de sus obras teatrales es "Renacer", la cual narra la historia de una mujer afro que ha dejado de hablar, cantar y bailar por el dolor que le causó la muerte violenta de su hijo desaparecido y asesinado por los actores armados del conflicto en Tumaco.

Según la academica lba Jakeline Ruano, en esta iniciativa, el arte es usado como herramienta sanadora de la población de Tumaco, así como también de sensibilización, contribuyendo a la tranquilidad y a la esperanza de esta población (Alba Ruano, Entrevista Personal, 2015).

En la región Caribeña se destacan la iniciativa:

\section{La Corporación Cultural ATABAQUES, en Cartagena de Indias, Departamento de Bolívar.}

Esta organización de la sociedad civil tiene el objetivo de difusión y preservación de las manifestaciones artísticas, culturales, así como también de fortalecer socioculturalmente a los/las 
afrocolombianos/as a través de procesos de empoderamiento juvenil para la construcción de la paz.

La metodología utilizada es el desarrollo de las danzas y músicas tradicionales colombianas. Los resultados son fortalecimiento de la autonomía, mejora del auto concepto de sí mismos/as, además de fomentar y estimular la iniciativa y la creatividad de los/as participantes.

En la región Andina se ubican las siguientes iniciativas civiles de construcción de paz y empoderamiento:

\section{La Corporación Colombiana de Teatro, en Bogotá, Departamento de Cundinamarca.}

Es una entidad cultural sin ánimo de lucro con 40 años de experiencia e integrada por artistas teatrales. Los objetivos de esta fundación son la creación artística, la difusión, la formación y el trabajo cultural, pero además también participa en proyectos sociales.

La corporación apoya a las madres de las víctimas del conflicto armado colombiano, realizando un trabajo de restauración y recuperación de estas mujeres olvidadas por el Estado a través del teatro y talleres de música. Este proyecto dirigido por la directora de la corporación, Patricia Ariza, se denomina "Mujeres de Arte y Parte en la Paz de Colombia". Se trata de un lugar de encuentro con otras mujeres, con el arte y con la paz posible. Este proyecto se fue ampliando hasta conformar 12 grupos de mujeres, integrado por 140 mujeres realizando obras colectivas originales, en las que se explican los conflictos del país a través de la mirada de las mujeres. Durante la obra las mujeres claman por la verdad, la justicia y la reparación desde la perspectiva femenina, visibilizando también la exclusión de las mujeres.

Asimismo también la Corporación Colombiana de Teatro (CCT) realiza talleres de formación artística para la memoria compartida y el relato cultural con la población en situación de desplazamiento, con el resultado de creación de relatos de los hechos de la guerra colombiana a través de la voz de desplazados/as.

\section{El Colectivo Dexpierte, con sede en Bogotá, Departamento de Cundinamarca.}

Se trata de un proyecto de investigación de experimentación artística de resistencia frente al olvido y por la memoria histórica. Se definen como una acción colectiva, haciendo uso de lo visual a través de la gráfica.

El colectivo se compone de tres hombres y una mujer. Una de las integrantes de este colectivo es Ana María Cuesta, persona que fue entrevistada en el marco de esta investigación.

Los/as participantes suelen ser niños/as, mujeres y campesinos/as. La metodología utilizada por el Colectivo es realizar memoria a través de la técnica artística del grafiti, también de la fotografía y el esténcil y pintar en las paredes publicas los rostros de los/as desaparecidos/as en el marco del conflicto armado colombiano, realizando así memoria histórica a partir de esta técnica artística.

Cabe destacar que Dexpierte también trabaja la temática de las mujeres víctimas del conflicto, a través de la realización de acciones artísticas conjuntamente, denominándolo gráfica 
popular. Ana María Cuesta, al describir esta iniciativa nos permite entender el approach del arte para la construcción de paz:

"En alguna ocasión estábamos en Barranquilla y pintamos un muro en plena avenida principal con 42 nombres de sindicalistas asesinados en Barranquilla, seguramente si nosotros hubiéramos cogido una tarima y un micrófono a decir los 42 nombres de los sindicalistas nos hubieran amenazado o no nos hubieran dejado a hablar; pero como lo estábamos haciendo a través de un muro obligaba a la gente que pasaba por la avenida nos preguntaran quiénes eran y hacer consciencia de lo que estaba pasando. Entonces eso es lo que permite el arte y la creatividad, decir lo políticamente incorrecto en unos espacios de una manera agradable, que te haga también reflexionar y que rompe con lo discursivo y quizás como violento." (Ana Maria Cuesta. Entrevista Personal, 2015).

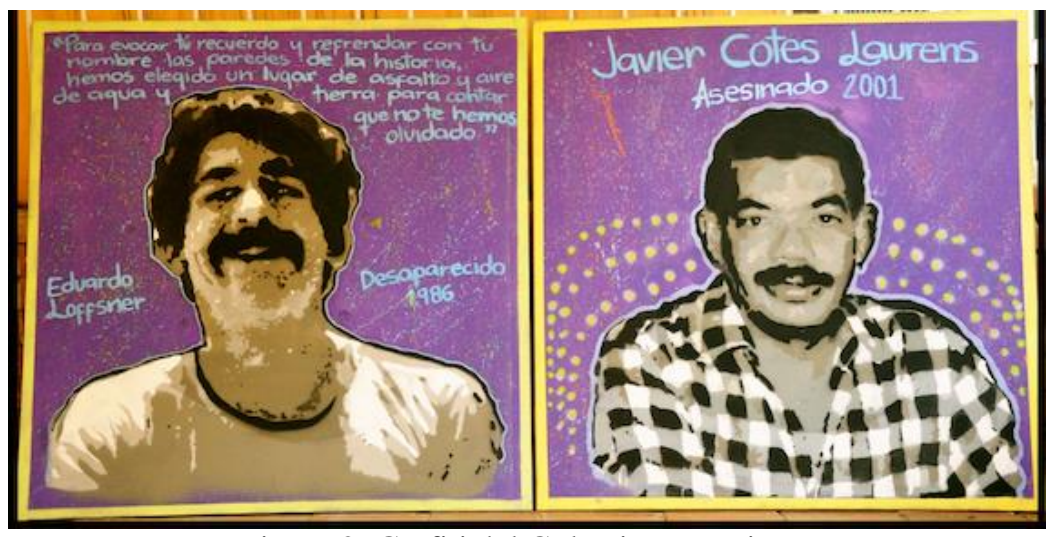

Figura 2: Grafiti del Colectivo Dexpierte.

Fuente: Fotografía cedida por la organización.

\section{El colectivo Carnavalenguas, en la ciudad de Medellín, Departamento de Antioquia.}

Esta iniciativa colectiva tiene la finalidad de reivindicar el derecho de las mujeres a una vida libre de violencias y fortalecer sus capacidades expresivas, artísticas y culturales, a través de la realización de acciones de sensibilización, prevención y sanación de las violencias hacia las mujeres y tejiendo memoria histórica a través de un carnaval de expresiones artísticas con mujeres del Valle del Cauca, Chocó, Santander, Caribe y Antioquia.

La metodología de trabajo del Carnavalenguas consta de dos fases:

-FASE 1. En primer lugar, se celebra concurso de las lenguas, voces y letras de las mujeres, a través de cuentos, poesías, alabaos, canciones populares, etc. De este concurso se eligen 13 propuestas para grabar un CD con el objetivo de presentarse el 25 de noviembre por el Día Internacional Contra la Violencia Contra la Mujer, en cada una de las regiones.

- FASE 2. La segunda fase es el denominado gran encuentro nacional, en la cual a través de los carnavales se identifica las costumbres que naturalizan las violencias hacia las mujeres, y al mismo tiempo rescata la alegría a través de antifaces, máscaras y mándalas, también con el objetivo de con-memorar a las víctimas de feminicidio y reclamar verdad y justicia por las víctimas del conflicto armado colombiano.

En la región Amazonía se destacan las siguientes iniciativas: 


\section{Los niños de Belén de los Andoques, Departamento de Caquetá.}

Es una escuela de audiovisual infantil (EAI) y un proyecto de comunicación comunitaria donde los niños/as muestran sus experiencias sobre la violencia desde el dibujo y el audiovisual, con el objetivo de que logren ampliar su proyecto de vida y alejarse de las consecuencias del conflicto. Cabe destacar que el grupo es apoyado por académicos y profesionales que trabajan en los campos de la televisión, el cine y la academia.

El lema de la EAI es "Sin historia no hay cámara", y tiene el objetivo de que los/as niños/as registren sus experiencias y su territorio. Algunas de sus producciones han sido el retrato de Belén, relatos del camino andaquí y películas al derecho.

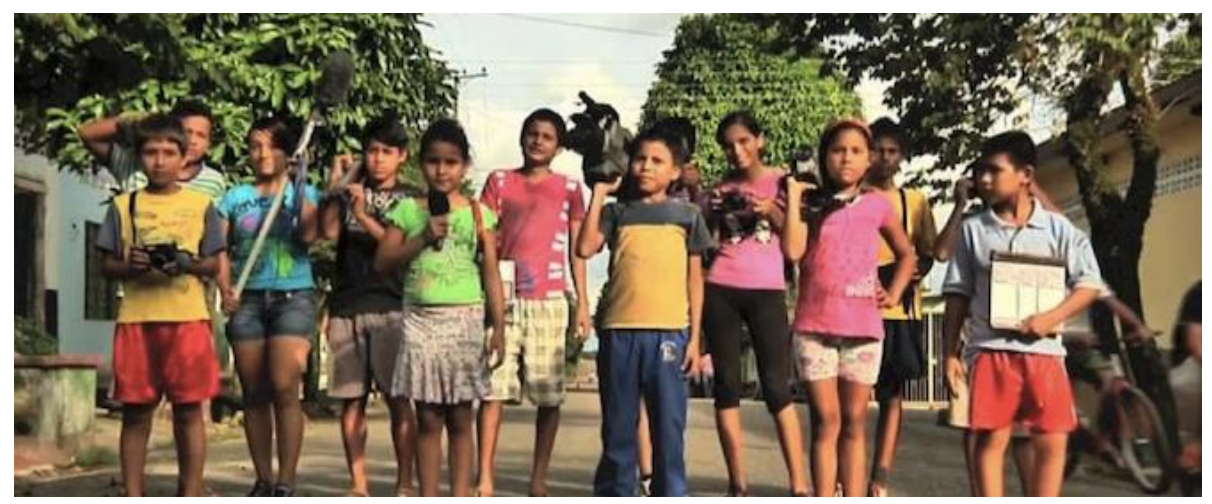

Figura 2: Fotografía de los niños/as participantes de la EAI Fuente: Imagen de Google EAI.

\section{La Asociación Mujeres del Municipio (ASMUN), en Caicedo, Putumayo.}

ASMUN se define feminista y pacifista, la conforman diversos colectivos de mujeres del municipio de Caicedo. Dicha iniciativa utiliza herramientas como movilizaciones culturales y pacíficas, que les permitan a las mujeres recuperar su autoestima y fortalecer habilidades para realizar acciones de denuncia y judicialización de los victimarios, así como también reconocer historias comunes de las mujeres. El impacto es que las mujeres participantes enriquecen su visión estratégica y la creatividad (Meneses, 2014, p. 77).

A nivel de ámbito nacional se encuentran las siguientes iniciativas de la sociedad civil colombiana:

\section{La Ruta Pacífica de las Mujeres.}

Es un movimiento feminista y pacifista a nivel nacional que tiene entre sus objetivos; la visibilización de los efectos de la guerra en la vida de las mujeres y la exigibilidad de los derechos a la verdad, la justicia, la reparación y la reconstrucción de la memoria histórica individual y colectiva para la no repetición. Además, la organización trabaja para que las mujeres no sean solo víctimas, sino también actoras sociales y políticas del proceso de negociación y de construcción de la Paz (Rettberg, 2006, p. 68).

Cabe añadir que la Ruta Pacífica se compone de más de 300 organizaciones y grupos de mujeres de nueve regiones: Antioquia, Bogotá, Bolívar, Cauca, Chocó, Putumayo, Risaralda, Santander y Valle del Cauca. 
Según Martha Giraldo, coordinadora de la Ruta Pacifica de las Mujeres y persona entrevista en el marco de este trabajo: La Ruta Pacífica de las Mujeres utilizan metodologías de trabajo simbólico a través del arte y de las identidades históricas. Una de estas metodologías es la audiovisual a través de documentales con la finalidad de generar concientización y reflexión acerca de las violaciones de derechos humanos. Igualmente, la Ruta también trabaja a través de rituales donde las mujeres danzan, o también rituales en los cuales las mujeres indígenas realizan limpias. Se trata de prácticas para liberar el perdón y para la reconciliación, en las cuales las técnicas creativas y artísticas son herramientas efectivas para la liberación de las emociones (Giraldo: Entrevista, 2015).

\section{La Corporación Otra Escuela (COE) en la ciudad de Bogotá, Departamento de Cundinamarca.}

COE es una organización de la sociedad civil colombiana, la cual ya ha sido presentada en el apartado de justificación del presente Trabajo Fin de Máster. La misma trabaja a través de procesos formativos y desarrollo de proyectos a través de técnicas artísticas y lúdicas.

La metodología utilizada por COE es la metodología socio-afectiva o también denominada vivencial que está orientada en la línea de la educación popular de Paulo Freire con 4 etapas, en las áreas de paz o empoderamiento, siendo las siguientes:

- Etapa 1. En primer lugar, se realiza una vivencia a través de un ejercicio, que puede ser lúdico o una práctica artística, como puede ser el teatro.

- Etapa 2. En segundo lugar, se realiza una reflexión con los/as participantes, en los cuales ellos/as son protagonistas y se habla de la experiencia vivida desde el "yo", y se expresa lo que se ha sentido o se ha aprendido a través del ejercicio. A partir de lo que se comunica por los/as participantes, también sirve al resto de participantes ya que se pueden sentir identificados con el relato.

- Etapa 3. En tercer lugar, el/la facilitador/a explica las razones de la realización del ejercicio específico y se relaciona con teorías académicas. A raíz de la vivencia, las personas se sienten más involucradas e identificadas con la teoría y el discurso porque existe una vinculación afectiva, a través de la emoción, la cual tienen una fijación más profunda en la memoria.

- Etapa 4. En cuarto lugar, se realiza la contextualización, ya que lo que se pretende es que con la información recibida y la vivencia, ésta sea utilizada para la transformación social y la resolución pacífica de conflictos.

Según Mar Maiques, coordinadora de proyectos de la Corporación Otra Escuela, y persona entrevistada en el marco de la presente investigación:

Uno de los objetivos de esta metodología, es que las personas puedan expresarse por sí mismas en colectivo, que se posicionen y actúen, basado en la filosofía de la educación popular de Paulo Freire. Por ejemplo, una de las prácticas artísticas que utilizamos es el teatro de los/as oprimidos/as, ya que encaja perfectamente con la metodología socioafectiva. Igualmente, también usamos la expresión corporal, la música, el dominar el cuerpo, moverlo, lo plástico, pinturas, material reciclado, el barro, están son las que más usamos (Mar Maiques, Entrevista Personal, 2015). 
Según Maiques, las técnicas anteriormente citadas producen que las personas expresen su propia realidad, su historia y experiencia, son resultados muy positivos en las personas que las practican, ya que se trabaja "la autoestima, la auto identificación, la cooperatividad, la comunicación no violenta, aprender a tomar decisión por consenso, tener una actitud cooperadora, no personalizar los problemas, de todo esto surge la creatividad y a partir de aquí se produce la transformación positiva de conflictos y la humanización de las relaciones" (Mar Maiques, Entrevista Personal, 2015).

\section{Conclusiones Preliminares}

En el gran universos de iniciativas civiles, de base social y organizaciones de la sociedad civil que trabajan por la construcción de paz en Colombia, muchas demuestran el compromiso de reconocer, dignificar y reparar integralmente a las víctimas del conflicto armado, demostrando que es posible la construcción de una verdadera transformación hacia la paz y que esta transformación sea a través del arte, siendo este un camino viable para buscar medios concretos hacia la superación de injusticias y discriminaciones.

Asimismo, a través de esta investigación se han visibilizado, reconocido y sistematizado los procesos territoriales de construcción de paz y empoderamiento a través de técnicas creativas, artísticas y vivenciales, destacando los liderados por mujeres. Estas iniciativas son propuestas contra la impunidad, apuestas a favor de la memoria colectiva y en defensa de los derechos humanos en Colombia, ya que a través de estas prácticas estético-artísticas las víctimas visibilizan y denunciar su situación y condición a raíz del conflicto armado colombiano.

Igualmente, es importante citar que las metodologías artísticas, creativas y vivenciales mencionadas durante este trabajo, logran que haya una transición y empoderamiento de las personas de víctimas a constructores de paz. Además, también se demuestra que las técnicas creativas y artísticas posibilitan que las víctimas del conflicto armado colombiano trabajen sus subjetividades a partir de lo simbólico; y que el arte es una estrategia efectiva de transformación y resignificación del dolor y del sufrimiento en el proceso del duelo, ya que la expresión artística se convierte en una forma de comunicación de sus propias vivencias, miedos o alegrías y de transmisión de sentimientos y emociones. Asimismo también estas metodologías y técnicas creativas y artísticas son herramientas eficaces para la construcción de memoria histórica.

Por último, las técnicas creativas, artísticas y vivenciales son un medio para el empoderamiento ya que aumentan su autoestima, pasando a ser un sujeto de derechos, donde perciben la posibilidad de expresarse y de ser escuchado.

Preliminarmente se ha observado, al analizar las iniciativas aquí expuestas que las técnicas y metodologías creativas, artísticas y vivenciales pueden tener un impacto positivo para la transformación social y la visibilización de las violaciones de derechos humanos y la construcción de memoria histórica y aún más en el contexto actual donde los procesos de sanación y de expresión creativa y artística de la población colombiana son necesarios para una paz transformadora, perdurable e inclusiva en Colombia y deben cada vez más ganar su debida atención dentro de los estudios de paz, conflicto y desarrollo.

\section{Bibliografía}


Cuesta, Ana María. (2015). Entrevista a Ana María Cuesta. Integrante del colectivo Dexpierte. Quito, 3 de Octubre del 2015.

Giraldo, Martha. (2015). Entrevista a Martha Giraldo. Coordinadora de La Ruta Pacífica de las Mujeres. Quito, 28 de Septiembre de 2015.

Maiques, Mar. (2015). Entrevista realizada a Mar Maiques. Coordinadora del área de formación y proyectos de la Corporación Otra Escuela. Quito, 11 de Septiembre de 2015.

Ruano, Alba Jakelin. (2015). Entrevista a Alba Jakeline Ruano. Socióloga y profesora de la Universidad de Nariño. Quito, 30 de Septiembre de 2015.

Bryman, A. (2005). Social Research Methods, Oxford, UK: Oxford University Press.

Foucault, M. (1979). Microfísica do Poder, Rio de Janeiro, Ed. Graal.

Foucault, M. (2006). Arqueología do Saber, Rio de Janeiro, Ed. Forense Universitaria.

Gómez González, A. Diez Palomar, J. (2009). Metodología comunicativa crítica: Transformaciones y cambios en el S.XXI, Revista electrónica Teoría de la Educación, Educación y cultura en la era de la Información, Universidad de Salamanca, pp. 103-118.

González Sánchez, G. (2008). Trujillo, una tragedia que no cesa Introducción general. Bogotá: CNRR: Planeta, Colección: Memoria Histórica CNRR, pp. 11-14.

Hernández Delgado, E. (1988). Resistencias para la paz en Colombia, experiencias indígenas, afrodescendientes y campesinos. Revista de paz y conflictos, Granada, Universidad de Granada, pp. 117-135.

Mejía, V. (2015). La educación artística como experiencia de paz imperfecta. Revista de Estudios de Sociedad, Arte y Gestión. Tercio Creciente, núm. 8, pp. 7-16.

Meneses, J. E. (2014). Gestando la paz- haciendo memoria. Iniciativas locales de construcción de paz en Colombia desde la perspectiva de las mujeres. Bogotá, UN WOMEN.

Muñoz López, P. (2013). Arte Feminista. Empoderamiento de las mujeres en el arte. El ejemplo de Paula Rego. Cuadernos Koré. Revista de historia y pensamiento de género, $n^{\circ} 8$ (Primavera-Verano 2013), Madrid, Universidad Autónoma de Madrid, pp. 237-265.

Ocampo, R. J. (2010). La Paz como construcción ético-política de base. Universidad Autónoma de Occidente, Cali, Revista Nova et Vetera, Políticas Públicas y Derechos Humanos, vol. 19 nº 63, PP. 49-59.

Kabeer, N. (2000). Reflections on the Measurement of Women's Empowerment. Discussing Women's Empowerment. In Discussing Women's Empowerment: Theory and Practice. SIDA studies (3). SIDA, Stockholm, Sweden.

Rettberg, A. (2006). Buscar la paz en medio del conflicto, un propósito que no de tregua: un estudio de las iniciativas de paz en Colombia (Desde los años 90 hasta hoy). Universidad de los Andes, Bogotá, CESO, PNUD, pp.9-52.

Ruiz, A. (1999). Metodología de la investigación Educativa. Bilbao, Ed. Grifo Chapecó, 1999.

Sampieri, R. H; et. Al. (2003). Metodología de la Investigación. México, D. F Ed. McGraw-Hill Interamericana.

Silva, J. S. (2012). La violencia en Colombia: una perspectiva desde el arte. Pereira, Universidad Tecnológica de Pereira/ Colciencias, Colombia, Revista nodo No 13, Vol. 7, Año 7: 43-56 JulioDiciembre 2012, pp. 43-56.

Toro, A. (2014). El Palíndromo de Antígona, o el empoderamiento pacifista a través del Arte. Universidad del Valle, Revista Nexus comunicación, nº 16, pp. 147-163. 